\title{
Status of the EU DEMO HCLL breeding blanket design development
}

\author{
Julien Aubert $^{\mathrm{a}, *}$, Giacomo Aiello ${ }^{\mathrm{a}}$, Pietro Arena ${ }^{\mathrm{b}}$, Tom Barrett ${ }^{\mathrm{c}}$, Lorenzo Virgilio Boccaccini ${ }^{\mathrm{d}}$, \\ Gaetano Bongiovì $^{\mathrm{b}}$, Rémi Boullon ${ }^{\mathrm{a}}$, Fabio Cismondi ${ }^{\mathrm{e}}$, Ion Critescu ${ }^{\mathrm{d}}$, Phani Kumar Domalapally ${ }^{\mathrm{f}}$, \\ Laurent Forest $^{\mathrm{a}}$, Jean-Charles Jaboulay ${ }^{\mathrm{a}}$, Béla Kiss ${ }^{\mathrm{g}}$, Alexandre Morin ${ }^{\mathrm{a}}$, Justine Peyraud ${ }^{\mathrm{a}, \mathrm{h}}$, \\ Gabor Porempovics ${ }^{\mathrm{g}}$, Marco Utili ${ }^{\mathrm{i}}$, Ladislav Vála ${ }^{\mathrm{J}}$.
}

${ }^{a}$ Den-Département de modélisation des systèmes et structures (DM2S), CEA, Université Paris-Saclay, F-91191 Gif-sur-Yvette, France

${ }^{b}$ Università di Palermo, Viale delle Scienze, 90128 Palermo, Italy

${ }^{c} U K A E A$ CCFE/RACE, Culham Science Centre, Abingdon, UK

${ }^{d}$ KIT, Karlsruhe Institute of Technology, Karlsruhe, Germany

${ }^{e}$ EUROfusion Consortium, PPPT Power Plant Physics and Technology, Garching, Germany

${ }^{f}$ Centrum výzkumu Řež, Hlavní 130, 25068 Husinec, Řež, Czech Republic

${ }^{g}$ Institute of Nuclear Techniques, Budapest University of Technology and Economics, Hungary

${ }^{h}$ Sorbonne Universités, UPMC Univ Paris 06, F-75005, Paris, France

${ }^{i}$ ENEA CR Brasimone, 40032 Camugnano, BO, Italy

In the framework of the European "HORIZON 2020" innovation and research programme, the EUROfusion Consortium develops a design of a fusion power demonstrator (DEMO). One of the key components in the fusion reactor is the Breeding Blanket (BB) surrounding the plasma, ensuring tritium self-sufficiency, heat removal for conversion into electricity, and neutron shielding. CEA-Saclay, with the support of Wigner-RCP and Centrum výzkumu Řež, is in charge of the development of one of the four BB concepts investigated in Europe for DEMO: the Helium Cooled Lithium Lead (HCLL) BB. The rationales of the HCLL are the use of Eurofer as structural material, eutectic liquid lithium-lead (PbLi) as tritium breeder and neutron multiplier, and helium gas as coolant.

This paper shows the basic description of the DEMO HCLL BB concept and its design evolution during the past years, from a design based on the ITER Test Blanket Module (TBM) concept to a more advanced design called "Advanced-Plus" concept. This new HCLL BB concept that has been designed in order to improve Tritium Breeding Ratio (TBR) and shielding performances is presented. This new reference HCLL BB design has been analyzed and show very promising nuclear performances. Nevertheless, the "Optimized Conservative" concept, based on ITER TBM, is still considered as a robust back-up solution since structural improvements are still necessary on the "Advanced-Plus" concept. Moreover, a new Back Supporting Structure (BSS) is presented in this paper, designed to support the BB modules, with the aim to reduce pressure drops and thermal stresses.

Keywords: DEMO, HCLL, Breeding Blanket

\section{Introduction}

Europe is committed to the development of a near term fusion power plant based on limited technologies and plasma extrapolation from ITER. This so-called DEMOnstration reactor shall prove the feasibility of generating electricity with an integrated fusion plant [1]. In DEMO, the Breeding Blanket (BB) is a component surrounding the plasma which has to withstand severe loads while ensuring the following 3 functions: generate tritium for self-sufficiency, shield the magnets against neutrons and heat-up the coolant in a certain range of temperatures suitable for heat extraction in order to supply a turbine for producing electricity [1].

The Helium Cooled Lithium Lead (HCLL) is one of the four candidates of $\mathrm{BB}$ concepts selected by the European Union for DEMO [2] and planned to be tested in ITER as part of the Test Blanket Module (TBM) programme [3]. Within the EUROfusion organization, CEA with the support of Wigner-RCP and Centrum výzkumu Rež, is in charge of the design of the HCLL $\mathrm{BB}$ for DEMO. It is based on the use of Reduced Activation Ferritic/Martensitic (RAFM) steel Eurofer as structural material, the eutectic $\mathrm{Pb}-15.7 \mathrm{Li}$ enriched at $90 \%$ in ${ }^{6} \mathrm{Li}$ as tritium breeder and tritium carrier, and helium as coolant with inlet/outlet temperatures of 300/500 ${ }^{\circ} \mathrm{C}$ and $8 \mathrm{MPa}$ pressure.

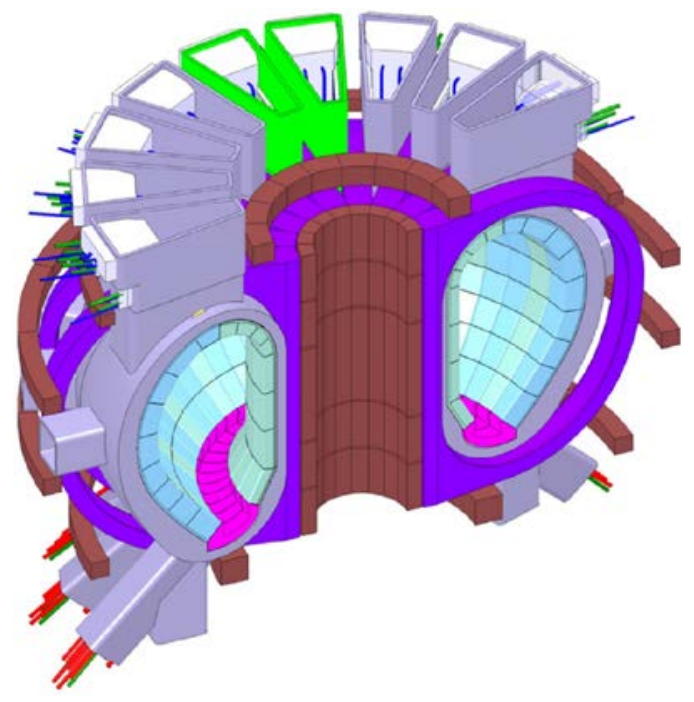

Fig. 1. HCLL BB in the $1 \frac{1}{2}$ DEMO 2015 baseline. 
This paper will present the design description of the HCLL BB and its evolution to achieve a new reference design, supported by some neutronic, thermal and mechanical analyses.

\section{Basic HCLL description}

The concept of the HCLL Breeding Blanket consists of several boxes stiffed by actively He-cooled plates, between which the PbLi breeder flows slowly. The DEMO baseline is evolving constantly. The description hereafter could be modified in the following years. The integration of the HCLL BB into the 2015 DEMO Tokamak baseline [4] is illustrated in Fig. 1. The latest $\mathrm{BB}$ system is divided into 18 identical sectors. Each sector is formed by 2 inboard (IB) and 3 outboard (OB) segments. Each BB segment consists of several box modules (8 modules in inboard and 9 modules in outboard, Fig. 2) attached together and composed of the following components/assemblies:

- An armour which typically consists of a tungsten protective layer of $2 \mathrm{~mm}$ in front of the boxes in order to prevent plasma erosion.

- A U-shaped First Wall (FW) which forms the front of the boxes made from Eurofer with a thickness suitable to withstand in-box Loss Of Coolant Accident (LOCA) in which are integrated the cooling channels in radial/toroidal/radial directions.

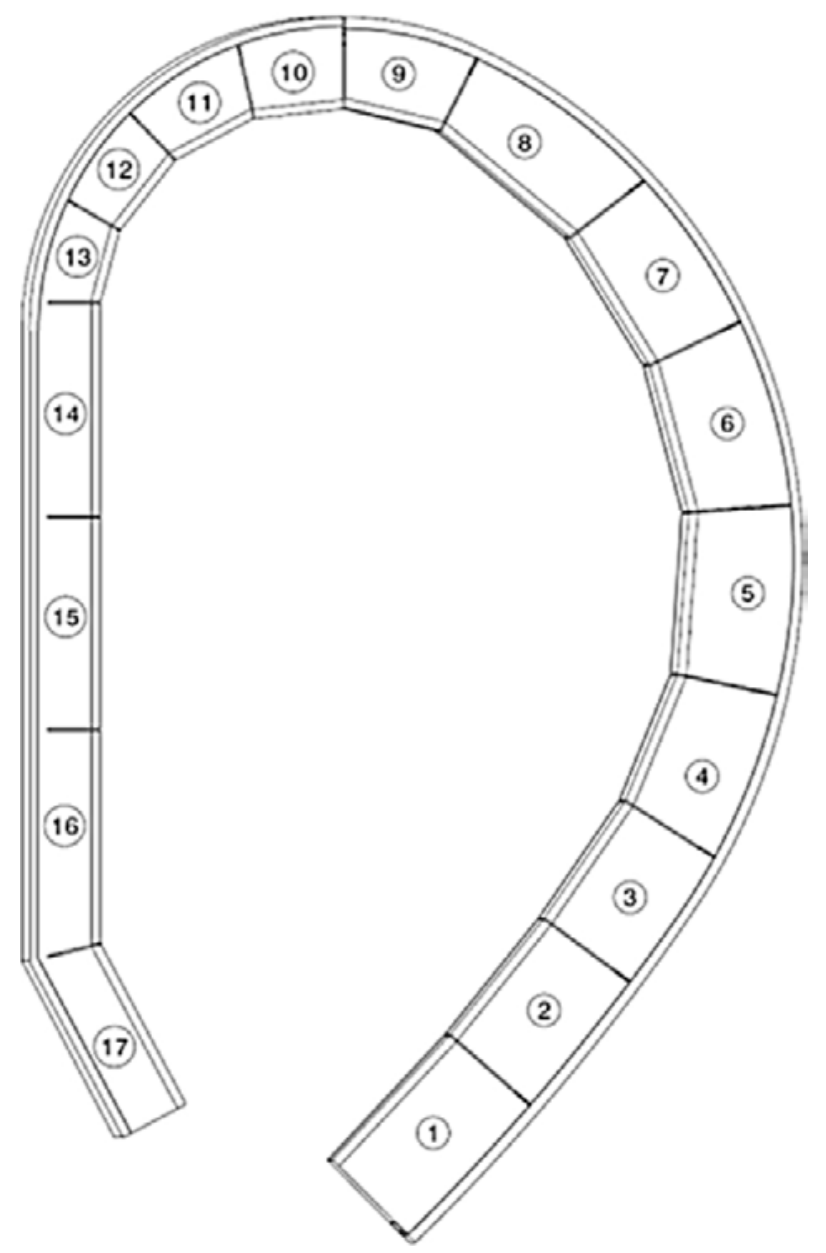

Fig. 2. Numbering of modules on DEMO 2015 Baseline.
- A Breeder Zone (BZ), behind the FW consists in $\mathrm{PbLi}$ breeder, upper and lower Caps to form the modules boxes at the top and bottom, Back Plate (BP) on the back to close the modules boxes, actively cooled Stiffening Plates (SP) with the function of: a) to stiffen the boxes delimitated by the FW, Caps and $\mathrm{BP}$ in case of in-box LOCA, b) to route the breeder/multiplier, and c) to remove the heat from the breeder/multiplier via integrated cooling channels and potentially Cooling Plates (CP) to remove the heat from the breeder/multiplier via integrated cooling channels.

- A Back Supporting Structure (BSS) with the functions to form several segments that can be removed from the upper port as a whole, to support all the blanket modules at the right position when attached to the $\mathrm{VV}$, to keep the integrity of the segment when the electro-magnetic (EM) loads occur due to plasma disruption, to distribute/collect the helium coolant and PbLi breeder to/from blanket modules as a manifold system, to participate to the neutron shielding for the Vacuum Vessel (VV) and the magnet coils. Some feeding pipes through the upper/lower ports are also present to connect the coolant and tritium carrier from the BSS to the Primary Heat Transfer System (PHTS) and TER.

The present design shows a poloidal segmentation of the segments into modules attached to the BSS, called Multi Modules Segment (MMS) concept. However, the design could be transformed to the Single Module Segment (SMS) approach if benefits are highlighted and drawbacks are justified.

\section{HCLL design evolution}

The original HCLL BB design developed within the EUROfusion consortium [5] was derived from the ITER HCLL Test Blanket Module (TBM) [3]. The so called "Optimized Conservative" concept, made of vertical and horizontal Stiffening Plates (vSP, hSP), and CP has been analyzed regarding thermal and mechanical behavior in Ref. [6] and has been demonstrated as a robust solution. However, this design offers very slight margin in term of tritium breeding [7], one of the key requirements for the DEMO BB to reach a Tritium Breeding Ratio (TBR) higher than 1.1 for ensuring the tritium self-sufficiency function [2]. In addition, more and more design constraints tend to reduce the tritium breeding volume [8]. Nevertheless, the "Optimized Conservative" HCLL concept is kept as a backup solution.

Thus, several HCLL BB concepts have been investigated in Ref. [7] view of TBR optimization, and two different HCLL BB concepts came out beside the "Optimized Conservative" design: the "Advanced" and "Advanced-Plus" designs. All the 3 designs are illustrated in Fig. 3 with their advantages and drawbacks. The "Advanced" concept is similar to the "Optimized Conservative” one, but vSPs have been removed. This concept has been analyzed in Refs. [9,10] regarding respectively thermal and mechanical behavior but has been discarded because of the poor TBR benefit [7] following the design modifications needed to cope with 


\begin{tabular}{|c|c|c|c|}
\hline Concepts & $\begin{array}{l}\text { Optimized } \\
\text { Conservative }\end{array}$ & Advanced & Advanced-Plus \\
\hline & $-1-1-$ & --- & \\
\hline & $--1-1$ & --- & \\
\hline & 二 $=$ & 二三三 & \\
\hline & $=\neq=$ & $=$ 二 & \\
\hline & $= \pm$ & $\bar{E}=$ & 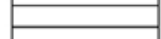 \\
\hline & hSP, vSP, $2 C P$ & hSP, 2 CP & hSP \\
\hline TBR & - & - & $+($ MMS $)++$ (SMS) \\
\hline PP & + & - & tor- \\
\hline $\begin{array}{l}\text { Shielding(Manifold } \\
\text { simplification) }\end{array}$ & - & + & ++ \\
\hline $\begin{array}{l}\text { Risk not to achieve } \\
\text { high requirements }\end{array}$ & High & Medium & Low \\
\hline $\begin{array}{l}\text { Risk not to fulfill } \\
\text { design criteria }\end{array}$ & Low & High & Very High \\
\hline
\end{tabular}

Fig. 3. Considered HCLL BB module concepts and their risk analyses.

the RCC-MRx design criteria: TBR gains regarding vSP removal is lost with thick Caps that withstand the pressure in case of LOCA $([10,16])$. Instead, the "Advanced-Plus" design in which vSPs and CPs have been removed, keeping only thin hSPs, is being further studied showing some good perspectives. This concept is considered now as the reference HCLL BB design.

\section{Reference “Advanced-Plus” HCLL BB design description}

The design of the "Advanced-Plus" HCLL equatorial outboard module (module 5 in Fig. 2) is shown in Fig. 4. The main characteristics are the presence of thin horizontal Stiffening Plates (hSP) of $5 \mathrm{~mm}$ each, separated by a $35.4 \mathrm{~mm}$ thick PbLi layer. These modifications permit to reduce the number of helium manifolds from three to only one. Caps have seen their thickness increased from $25 \mathrm{~mm}$ to $75 \mathrm{~mm}$ to withstand the pressure in case of in-box LOCA.

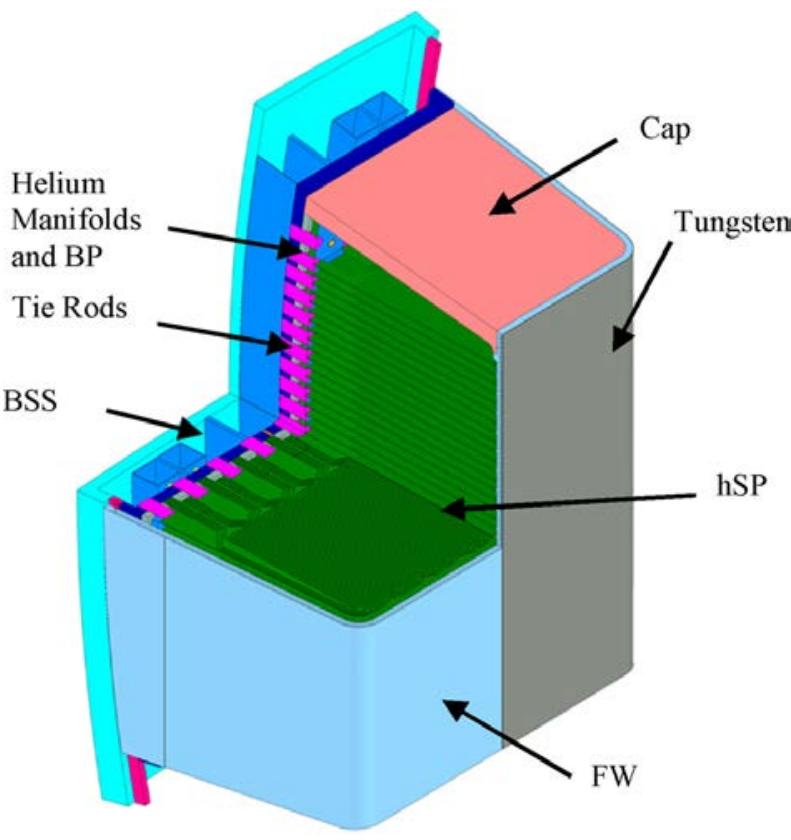

Fig. 4. Isometric view of 3/4 equatorial outboard module (Module 5).
A new design of the BSS came out with the aim to reduce pressure drops, to have a better shielding performance and to keep the temperature of the BSS structure as low as possible in order to reduce thermomechanical stresses. Iterations between design and neutronic analyses [7] have allowed an increase of the inboard BSS radial thickness in order to reduce pressure drops while keeping high enough the overall TBR. Massive CFD calculations have been performed to optimize the geometry which allowed a reduction of pressure drops in the inboard by a factor of 10 [12]. The resulting final design of the BSS is shown in Fig. 5. The BSS is constituted by a poloidal banana-shaped structure where 2 independent Helium Inlet and 2 independent Helium Outlet volumes are designed on both sides, plus 2 volumes for PbLi inlet and outlet in the middle of the structure.

The size of the PbLi volumes is based on a maximum $\mathrm{PbLi}$ velocity of $5 \mathrm{~cm} / \mathrm{s}$ considering a minimum of 10 recirculations per day. The outlet helium channels are placed in the middle of the inlet channels in order to keep the BSS Eurofer structure as low as possible to reduce thermo-mechanical stresses. Thermal behaviour of inboard and outboard BSS is detailed in Ref. [12]. Radial walls have been designed inside the manifolds in order to cope with pressure loads. In order to reduce pressure drops and to balance the mass flow rate all along the poloidal direction, the cross section of all the helium and PbLi manifolds are pyramidal. The helium reinforcements have to be perforated to allow the helium flows out from the inner into the outer chamber. The helium flows through small sized pipes from the modules into the BSS helium outlet manifold.

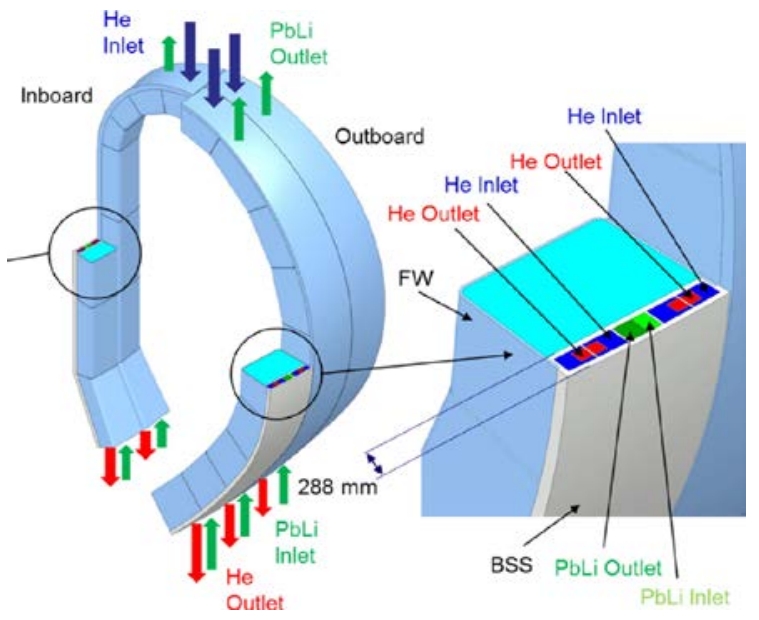

Fig. 5. CAD model of a sector showing the inboard and outboard BSS.

The helium and PbLi flow scheme is presented in Fig. 6. Helium flows in parallel in each module thanks to the BSS and in series inside each module. Helium enters the BB thanks to 2 pipes per segments through the upper port of the VV. Once helium is in the BSS inlet manifolds at $300{ }^{\circ} \mathrm{C}$, it is routed directly to the $\mathrm{FW}$ rectangular cooling channels on its both sides in order to provide counter current flow. Then helium goes out of the FW to the Manifolds MF1 on the back of the module 
and is being distributed in the cooling channels of the hSP and Caps. Then helium exits the modules to the outlet BSS manifold at $500{ }^{\circ} \mathrm{C}$ and is routed out of the segments thanks to 2 pipes through the lower port. PbLi flows in parallel in each module thanks to the BSS. PbLi enters the BSS thanks to 1 pipe through the lower port of the $\mathrm{VV}$ and then is routed to half of the modules slices in parallel. PbLi flows between two hSPs frontward (radially), and goes to the slice above through 7 rectangular holes $(72 \times 10 \mathrm{~mm})$ designed every two hSPs, on the back of the FW, and then radially flows backwards and is finally collected in the BSS. The integration of the HCLL BB with pipes into the Tokamak is presented in Fig. 7 for one sector.

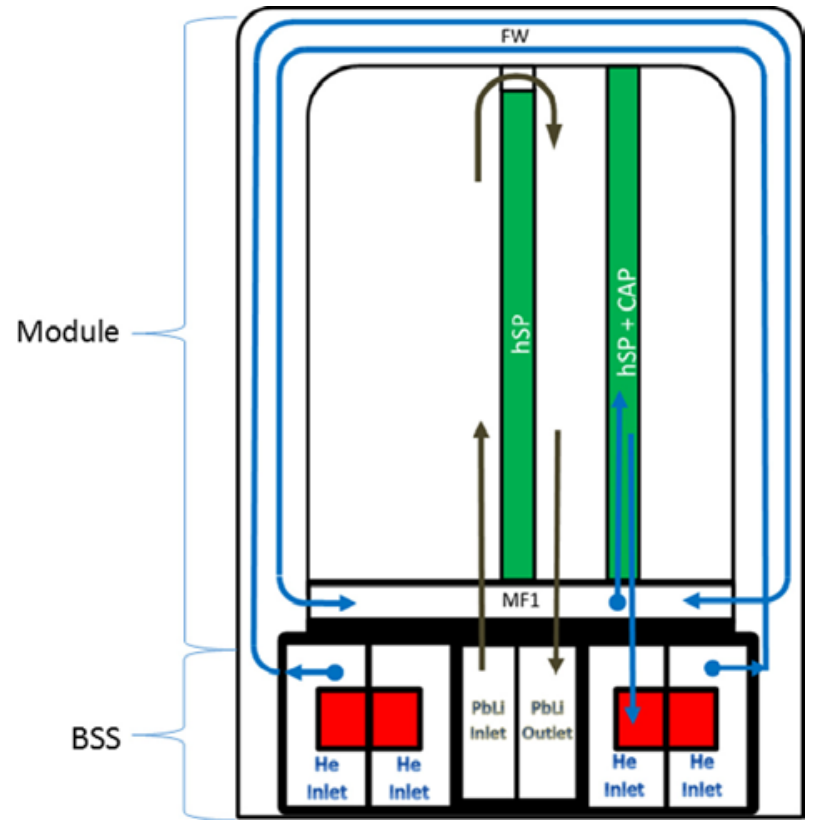

Fig. 6. He and PbLi distribution scheme.

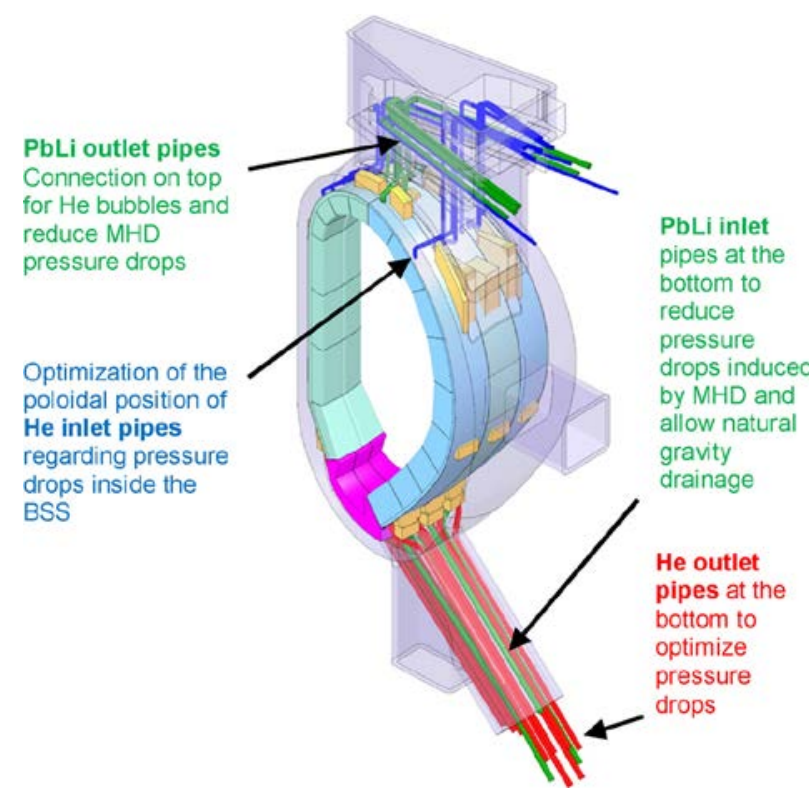

Fig. 7. Integration of the HCLL BB in a sector of the Tokamak.

The cooling system has been dimensioned in order to extract deposited power from neutrons and heat flux (HF) from plasma while insuring inlet/outlet temperatures of the helium coolant of respectively 300 ${ }^{\circ} \mathrm{C} / 500{ }^{\circ} \mathrm{C}$. Values of recovered power and associated helium mass flow rates are given in Table 1.

Values are calculated for the outboard and inboard segments considering the average HF value of 0.22 $\mathrm{MW} / \mathrm{m}^{2}$ on all the modules [4]. These values of mass flow rate are those used for the PHTS design. Pressure drops in the BSS have been calculated based on the aforementioned mass flow rates thanks to some CFD analysis up to the VV ports [12].

For the design and analysis of the equatorial outboard module (module 5, see Fig. 2), the power recovered and associated mass flow rate of $4.57 \mathrm{~kg} / \mathrm{s}$ have instead been calculated assuming the actual (average) HF of 0.5 $\mathrm{MW} / \mathrm{m}^{2}$ [3] acting on the module. Associated pressure drops have been calculated thanks to analytical formulae for the simplest area (FW, hSP) and with detailed CFD analysis for the most complicated areas (In-module manifold) [13].

Maximum pressure drops are equal to $0.332 \mathrm{MPa}$ in outboard segment and to $0.230 \mathrm{MPa}$ in inboard segment respectively. The repartition of pressure drops in the HCLL BB is highlighted in Fig. 8. Notice that the major contribution comes from the BSS. The total pumping power (PP) within the VV has been calculated in Ref. [12] and is equal to $100 \mathrm{MW}$. It has been calculated considering the total mass flow rate and the maximum pressure drop calculated in each component of each segment.

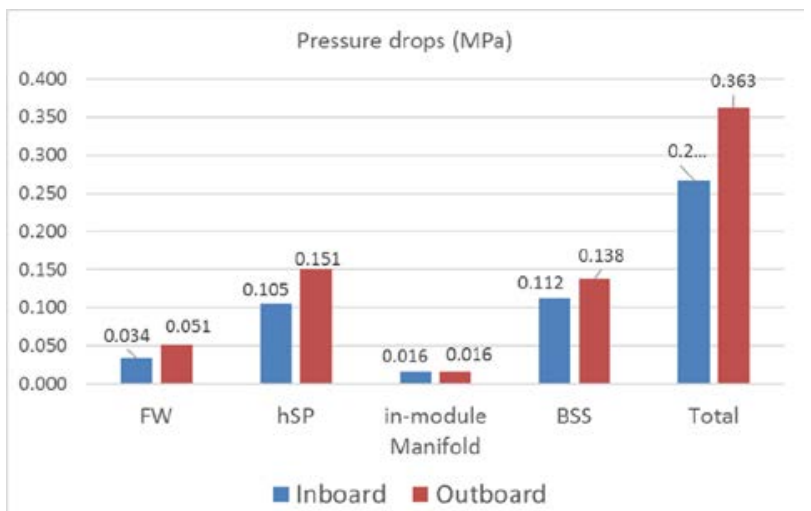

Fig. 8. Contribution of the component in the pressure drops calculation $[\mathrm{MPa}]$.

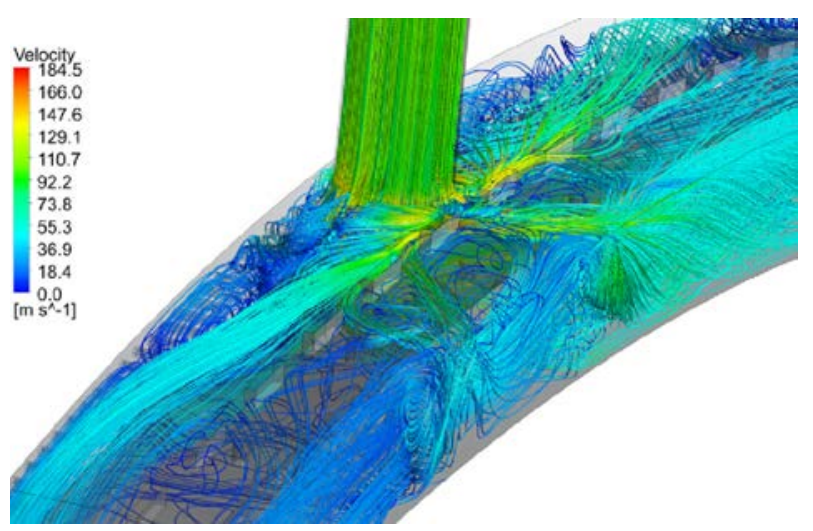

Fig. 9. Streamlines at connection of large helium inlet pipe Outboard. 
Table 1

Power deposited in the blanket modules and corresponding He mass flows for PHTS.

\begin{tabular}{|c|c|c|c|c|c|c|c|}
\hline & $\begin{array}{l}\mathrm{N}^{\circ} \text { of } \\
\text { modules }\end{array}$ & $\begin{array}{l}\text { Radiative Heat Flux } \\
{\left[\mathrm{MW} / \mathrm{m}^{2}\right]}\end{array}$ & $\begin{array}{l}\text { Radiative power } \\
{[\mathrm{MW}]}\end{array}$ & $\begin{array}{l}\text { Nuclear Power in modules } \\
\text { from } 2015 \text { baseline [MW] }\end{array}$ & $\begin{array}{l}\text { Nuclear Power in BSS } \\
\text { blocks from } 2015 \text { baseline } \\
\text { [MW] }\end{array}$ & $\begin{array}{l}\text { Total power } \\
\text { [MW] }\end{array}$ & $\begin{array}{l}\text { Mass flow- } \\
\text { rate }[\mathrm{kg} / \mathrm{s}]\end{array}$ \\
\hline \multirow{9}{*}{$\begin{array}{l}\text { OUTBOARD modules ( } 9 \\
\text { modules) }\end{array}$} & 1 & 0.22 & 0.42 & 1.78 & 0.017 & 2.22 & 2.15 \\
\hline & 2 & 0.22 & 0.41 & 2.40 & 0.025 & 2.84 & 2.77 \\
\hline & 3 & 0.22 & 0.43 & 2.69 & 0.026 & 3.15 & 3.06 \\
\hline & 4 & 0.22 & 0.44 & 2.88 & 0.028 & 3.35 & 3.25 \\
\hline & 5 & 0.22 & 0.54 & 3.45 & 0.032 & 4.02 & 3.91 \\
\hline & 6 & 0.22 & 0.50 & 3.13 & 0.029 & 3.66 & 3.56 \\
\hline & 7 & 0.22 & 0.46 & 2.72 & 0.026 & 3.21 & 3.13 \\
\hline & 8 & 0.22 & 0.47 & 2.58 & 0.045 & 3.09 & 3.02 \\
\hline & 9 & 0.22 & 0.24 & 1.30 & 0.028 & 1.57 & 1.52 \\
\hline Outboard segment & & & 3.91 & 22.93 & 0.255 & 27.09 & 26.38 \\
\hline \multirow{8}{*}{$\begin{array}{l}\text { INBOARD modules ( } 8 \\
\text { modules) }\end{array}$} & 10 & 0.22 & 0.29 & 1.43 & 0.058 & 1.78 & 1.76 \\
\hline & 11 & 0.22 & 0.25 & 1.19 & 0.075 & 1.52 & 1.52 \\
\hline & 12 & 0.22 & 0.23 & 0.994 & 0.054 & 1.28 & 1.26 \\
\hline & 13 & 0.22 & 0.18 & 0.774 & 0.043 & 1.00 & 0.97 \\
\hline & 14 & 0.22 & 0.51 & 2.28 & 0.110 & 2.90 & 2.85 \\
\hline & 15 & 0.22 & 0.51 & 2.56 & 0.122 & 3.19 & 3.13 \\
\hline & 16 & 0.22 & 0.51 & 2.09 & 0.103 & 2.71 & 2.66 \\
\hline & 17 & 0.22 & 0.47 & 1.78 & 0.089 & 2.34 & 2.28 \\
\hline Inboard segment & & & 2.96 & 13.10 & 0.653 & 16.71 & 16.42 \\
\hline $\begin{array}{l}\text { REACTOR (54x9) + } \\
(36 \times 8) \text { modules }\end{array}$ & & & 317 & 1710 & 37 & 2065 & 2016 \\
\hline
\end{tabular}

\section{5. “Advanced-Plus” HCLL design analyses}

Neutronic analyses presented in Ref. [8] based on the TRIPOLI-4® Monte Carlo code [14] show that the new HCLL “Advanced-Plus" design is very promising in terms of nuclear performance. Requirements are met both regarding the TBR presenting comfortable margin (1.15) and the inboard shielding for which criteria are fulfilled.

The "Advanced-Plus" HCLL equatorial outboard module has also been analyzed in Ref. [11] using Cast3M Finite Element Method code [15] regarding thermal and mechanical behavior respectively in normal and accident condition following the RCC-MRx rules [16]. This concept shows an overall good behavior, however some structural improvements are necessary especially on the Cap to improve its cooling and to make its connection with the FW stiffer for LOCA event.

The thermal behavior of the BSS has been analyzed in detailed in Ref. [12]. CFD calculations have been performed to assess the helium pressure drop, and thermal field related to the inboard and outboard BSS under steady state condition. ANSYS CFX [17] is used for the simulation. The numerical scheme used in this study is based on the Navier - Stokes equations. Turbulent flow was accounted for by the Shear Stress Transport (SST) turbulence model. Pressure drops in the BSS is summarized in Fig. 8. The flow field can be visualized by streamlines to understand the helium flow inside the BSS. The flow field is very chaotic at the connection of large helium inlet pipe (Fig. 9). For temperature distribution calculations, it is shown that for outboard BSS, the surface temperature are higher at the bottom of the structure (Fig. 10).

The temperature distribution is shown on $\mathrm{z}=0 \mathrm{~m}$ plane in the steel structure as well. For inboard, the surface temperature distribution shows that there are two zones with higher temperature on the $\mathrm{BB}$ side. The local temperature increment is caused by separation zones with low helium velocity. The separation is caused by the sudden change in flow direction because of the geometry. The implementation of an insulator inside the outlet channel could be studied in order to decrease the Eurofer temperature and to avoid heat transfer between cold and hot channels.

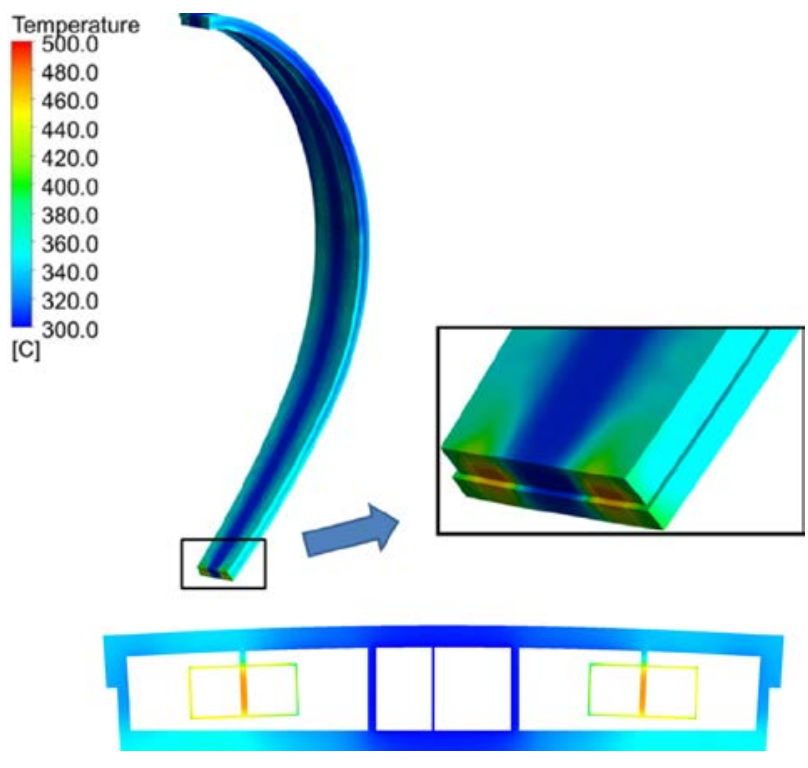

Fig. 10. Temperature distribution in the Outboard BSS Eurofer structure and close up on upper streamlines.

\section{Conclusion}

This paper shows the present status of the HCLL BB, which is one of the candidates for the EU DEMO BB. The design evolved during the past years, from a design based on the ITER TBM concept (which is still considered as a robust back-up solution) to a more advanced design called “Advanced-Plus" concept, now considered as the reference HCLL BB design. A new BSS has been designed to support the BB modules. However, even if this new concept shows good TBR and shielding capability, the design still has to be optimized in order to fulfil design criteria in normal and accidental conditions, especially in the Cap areas. 


\section{Acknowledgments}

This work has been carried out within the framework of the EUROfusion Consortium and has received funding from the Euratom research and training programme 2014-2018 under grant agreement No 633053. The views and opinions expressed herein do not necessarily reflect those of the European Commission.

\section{References}

[1] F. Romanelli, et al., Fusion Electricity -A Roadmap to the Realization of Fusion Energy, EFDA, 2012.

[2] L.V. Boccaccini, et al., Objectives and status of EUROfusion DEMO blanket studies, Fusion Eng. Des. 109-111 (2016) 1199-1206.

[3] G. Aiello, et al., HCLL TBM design status and development, Fusion Eng. Des. 86 (2011) 2129-2134.

[4] W. Ronald, DEMO1 Reference Design -2015 April (EU DEMO1 2015) - PROCESS One Page Output, Internal EURO Fusion Data.

[5] G. Aiello, et al., Development of the helium cooled lithium lead blanket for DEMO, Fusion Eng. Des 89 (2014) 1444-1450.

[6] G. Bongiovì, On the Thermal and Thermomechanical Assessment of the Optimized Conservative HeliumCooled Lithium Lead Breeding Blanket Concept for DEMO, This Conference (2018).

[7] J.-C. Jaboulay, et al., Nuclear analysis of the HCLL blanket for the European DEMO, Fusion Eng. Des. 124 (2017) 896-900.

[8] J.-C. Jaboulay, et al., Nuclear Analysis of the HCLL Advanced-Plus Breeding Blanket, This Conference, (2018).

[9] P. Arena, et al., Thermal optimization of the HeliumCooled Lithium Lead breeding zone layout design regarding TBR enhancement, Fusion Eng. Des. 124 (2017) 827-831.

[10] J. Aubert, et al., Thermo-mechanical analyses and ways of optimization of the helium cooled DEMO First Wall under RCC-MRx rules, Fusion Eng. Des. 124 (2016) 473-477.

[11] R. Boullon, et al., Investigation on the Advanced-Plus Helium Cooled Lithium Lead Breeding Blanket Design Concept for TBR Enhancement Regarding Thermal and Mechanical Behavior, This Conference (2018).

[12] J. Aubert, HCLL Design Description Document, (2016).

[13] P.K. Domalapally, Optimization of the Pressure Drops in the Helium Manifolds of the EU DEMO HCLL Breeding Blanket, This Conference (2018).

[14] TRIPOLI-4 Project Team, TRIPOLI-4 version 8 User Guide, CEA-R-6316, (2013) February http://www.oecdnea.org/tools/abstract/detail/nea-1716/.

[15] Cast3M. http://www-cast3m.cea.fr.

[16] RCC-MRx, Design and Construction Rules for Mechanical Components of Nuclear Installations, AFCEN, 2013.

[17] http://www.ansys.com/Products/Simulation+Technology/ Fluid+Dynamics. 